\title{
Effects of Kaolin Surface Treatments on the Thermomechanical Properties and on the Degradation of Polypropylene
}

\author{
Melia Guessoum, ${ }^{1}$ Sorya Nekkaa, ${ }^{1}$ Françoise Fenouillot-Rimlinger, ${ }^{2}$ \\ and Nacerddine Haddaoui ${ }^{1}$ \\ ${ }^{1}$ Laboratoire de Physico-Chimie des Hauts Polymères (LPCHP), Département de Génie des Procédés, Faculté de Technologie, \\ Université Ferhat Abbas, Sétif 19000, Algeria \\ ${ }^{2}$ Laboratoire des Matériaux Macromoléculaires, Institut National des Sciences Appliquées (INSA) de Lyon, \\ Domaine Scientifique de la Doua, Bâtiment Jules Verne, 17 avenue Jean Capelle, Villeurbanne, 69621 Lyon, France
}

Correspondence should be addressed to Melia Guessoum, guessoum_melia@yahoo.fr

Received 1 December 2011; Accepted 11 January 2012

Academic Editor: Jan-Chan Huang

Copyright (C) 2012 Melia Guessoum et al. This is an open access article distributed under the Creative Commons Attribution License, which permits unrestricted use, distribution, and reproduction in any medium, provided the original work is properly cited.

The effects of kaolin content and treatments on the thermal and mechanical properties and on the degradation of polypropylene were examined using mechanical tests, differential scanning calorimetry (DSC), and thermogravimetry (TGA). The weak interactions filler/matrix have been reinforced using a modification with urea then with an ammonium salt and a surface treatment with a silane coupling agent. The XRD results showed that the peak at the $d$-value of $10.7 \AA$ increases in urea/kaolin complex, but the treatment with the ammonium salt caused the return to the initial state of the clay. FTIR results showed the appearance of new bands characteristic of the interactions between urea and kaolinite and the alkylammonium and kaolinite. The mechanical properties of the composites exhibited important variations while the DSC results showed the decrease of the crystallization temperature as a function of kaolin content. TGA thermograms pointed out the improvement of the composites' thermal stability.

\section{Introduction}

In recent years, rapid growth and high consumption rates were predicted for various polyolefin composites, since they find applications in many areas such as automotive, home appliances, and construction. The use of mineral fillers in the fabrication of thermoplastic composites is mainly governed by price-performance relationships. Apart from reducing the price of the final material, mineral fillers can also help to improve shrinkage on moulding, stiffness and flammability, which are the principal limitations of the bulk thermoplastics. The effects of fillers on the mechanical and other properties of the composites depend on their shape, particle and aggregate sizes, surface characteristics, and degree of dispersion [1-3].

Polypropylene (PP) is one of the most frequently used polymers because of its low price, balanced properties, and easy processability. To improve some of its properties and thus widen its application range, blending with other polymers and/or fillers is the alternative that is usually employed in order to increase its strength, impact resistance and toughness. Among the inorganic fillers that are used to improve PP properties, clays are recognized to get several beneficial variations on stiffness, hardness, toughness, and heat resistance [2-4].

Kaolinite $\left(\mathrm{Al}_{2} \mathrm{Si}_{2} \mathrm{O}_{5}(\mathrm{OH})_{4}\right)$ is a $1: 1$ phyllosilicate containing a gibbsite octahedral layer and a silicon oxide tetrahedral sheet. This asymmetric structure allows the formation of hydrogen bonds between consecutive layers, providing a large cohesive energy. As the inorganic surface of the particles is highly polar while the PP is apolar, the interface interaction can be provided only by molecular modification of one or both components. So to get a good dispersion, the surface modification of kaolinite can be achieved either by the use of coupling agents, or by the intercalation of chemical species in the interlayer gallery, to increase the basal spacing of the 
clay which may facilitate the intercalation of polymer chains between its platelets [5-8].

Also, the number of the chemical species which can be directly inserted in the interlayer of the kaolinite is limited due to the great cohesive energy between the clay layers. The most known compounds that intercalate directly into kaolinite on contact with the clay are formamide, hydrazine, potassium acetate, dimethylsulphoxide (DMSO), and urea. Other compounds can also be introduced in the kaolinite interlayer by the displacement of a previously intercalated compound [9-13].

In the urea/kaolinite intercalation model proposed by Ledoux and White [14], urea forms hydrogen bonds on interacting with the silica plane and the inner surface hydroxyls via its $\mathrm{NH}_{2}$ groups. According to Frost et al. [15, 16], urea forms hydrogen bonds with the silica plane only. Also, Makó et al. [17] proposed a structural model comprising two types of urea bonding to the siloxane surface, involving the $\mathrm{NH}_{2}$ groups and the oxygen atom of the silica layer.

The inorganic fillers and their treatments induce variations on practically almost of the composites properties especially, mechanical and thermal characteristics. At high filler loading, it was noticed that the elastic modulus and the tensile strength increase while the deformation at break diminishes drastically due to the decrease of the deformability of the matrix [18]. The fillers affect also the crystallization behavior and the degradation process so an increase of the thermal stability of the composites compared to the virgin material is generally observed [19-21].

The aim of the present work is to study the effects of small concentrations of two types of modified kaolin, the first with an alkylammonium salt after passing by a treatment with urea and the second surface treated with a silane coupling agent, on the mechanical and thermal properties of PP composites.

\section{Experimental}

2.1. Materials. The polymer matrix used in this study was polypropylene "Moplen RP 320H" manufactured by Basell. It is a statistical copolymer, having a melt flow index experimentally determined to be $2.30 \mathrm{~g} / 10 \mathrm{~min}$ at $190^{\circ} \mathrm{C}$. Urea $\mathrm{NH}_{2} \mathrm{CONH}_{2}$ is a Prolabo product. The alkylammonium is a hexadecyltrimethylammonium chloride abbreviated as (HDTMA), purchased from Aldrich, and having the following chemical structure $\mathrm{CH}_{3}\left(\mathrm{CH}_{2}\right)_{15} \mathrm{~N}\left(\mathrm{CH}_{3}\right)_{3} \mathrm{Cl}$. The coupling agent used for kaolinite surface treatment is $\mathrm{N}$-[3trimethoxysilyl propyl] ethylene diamine commercialized by Aldrich under the abbreviation Z-6020. The used kaolinite has a micrometric dimension and the following chemical composition determined by chemical analysis, as it is reported in Table 1.

2.2. Kaolinite Treatments. The experimental method used for urea intercalation was already proposed by Letaief et al. [22]. It consists on a manual grinding in a mortar of a mixture of $5 \mathrm{~g}$ kaolinite and $8 \mathrm{~g}$ of urea for a period of 2.5 hours, followed by a mechanical grinding for 15 minutes.
TABLE 1: Chemical composition (wt\%) of the used kaolin.

\begin{tabular}{lc}
\hline $\mathrm{SiO}_{2}$ & 50.44 \\
\hline $\mathrm{Al}_{2} \mathrm{O}_{3}$ & 28.30 \\
$\mathrm{CaO}$ & 1.10 \\
$\mathrm{MgO}$ & 0.50 \\
$\mathrm{Fe}_{2} \mathrm{O}_{3}$ & 2.29 \\
$\mathrm{LOI}$ (loss on ignition) & 10.01 \\
\hline
\end{tabular}

For urea displacement from kaolinite, the resulting material was subjected to a reaction in a solution containing the ammonium salt at a temperature of $80^{\circ} \mathrm{C}$ for 24 hours. After That, the clay was filtered and dried then stored. Furthermore, a part of the unmodified clay was treated with two concentrations of the silane coupling agent Z-6020, dissolved in an aqueous medium, namely $2 \%$ and $4 \%$. Finally, the three as-treated samples as well as the unmodified kaolinite were characterized by Fourier transform infrared spectroscopy and X-ray diffraction.

2.3. Composites Preparation. The composite materials, with kaolinite amounts varying from 1 to 5 parts per hundred resin (phr), were prepared by mixing the polymer matrix and the ammonium modified and unmodified kaolinite, respectively, $\mathrm{PP} / \mathrm{TK}$ and $\mathrm{PP} / \mathrm{UK}$, in a two-roll mixer at a temperature of $190^{\circ} \mathrm{C}$ and a mixing rate of $30 \mathrm{rpm}$ for a period of 10 minutes. The same procedure was also followed to prepare $\mathrm{PP} /$ silane-treated kaolin composites (PP/KTS), using two clay concentrations, namely, 2 and 4 phr. After That, the obtained sheets were cut into small pieces then pelletized. For the mechanical tests samples preparation, the pelletized composites were compressed in a Davenport compression moulding machine at a temperature of $190^{\circ} \mathrm{C}$ and a compression pressure of $220 \mathrm{Kg} / \mathrm{cm}^{2}$ during 5 minutes.

\subsection{Measurements}

2.4.1. Infrared Spectroscopy. Fourier transform infrared spectroscopy (FTIR) spectra were obtained between 500 and $4000 \mathrm{~cm}^{-1}$ on a Shimadzu FTIR 8400 S. Ten scans were averaged at a resolution of $4 \mathrm{~cm}^{-1}$ for the solid tested samples of modified and unmodified kaolinite prepared as $\mathrm{KBr}$ pellets (ca. $3 \%$ by mass in $\mathrm{KBr}$ ).

2.4.2. X-Ray Diffraction. The X-ray diffraction (XRD) study on the modified and unmodified kaolin was carried out on an XPERT apparatus using $\mathrm{Cu}-\mathrm{k} \alpha(\lambda=1.54 \AA)$. All measurements were taken using a generator voltage of $45 \mathrm{kV}$ and a generator current of $30 \mathrm{~mA}$.

2.4.3. Mechanical Properties. Notched Izod impact strengths were measured on compressed samples using a CEAST pendulum instrument. To characterize the tensile characteristics of the hompolymer and its composites, namely, the stress and the elongation at yielding and at break $\left(\sigma_{y}\right.$ and $\left.\varepsilon_{y}\right)$ and $\left(\sigma_{r}\right.$ and $\left.\varepsilon_{r}\right)$, respectively, measurements were performed according to the norm ASTM D638, at a cross-head speed 
of $30 \mathrm{~mm} / \mathrm{min}$ on dumbbell samples using a Zwick Material prüfung 1445 .

2.4.4. Differential Scanning Calorimetry (DSC). DSC measurements were carried out on a TA instrument, according to the following program: the specimens were first heated from ambient temperature to $250^{\circ} \mathrm{C}$ at $10^{\circ} \mathrm{C} / \mathrm{min}$ maintained at this temperature during 5 minutes then cooled to $25^{\circ} \mathrm{C}$ at $20^{\circ} \mathrm{C} / \mathrm{min}$. Crystallinity was calculated according to the following equation:

$$
\chi_{c}(\%)=\frac{\Delta H_{c}}{\Delta H_{c}^{0}} \times 100 .
$$

A crystallization melting enthalpy of $100 \%$ crystalline PP $\Delta H_{c}^{0}=165 \mathrm{~J} / \mathrm{g}$ was used [23].

2.4.5. Thermogravimetric Analysis (TGA). The tests were performed on a TA instrument (TGA Q500) by heating the samples from 20 to $550^{\circ} \mathrm{C}$ at $20^{\circ} \mathrm{C} / \mathrm{min}$. From DTG thermograms giving the variations of the weight loss derivative as a function of temperature, we estimated the temperatures at which starts and finishes the degradation process $T_{\mathrm{d} 0}$ and $T_{\mathrm{df}}$, respectively, as well as $T_{\mathrm{dmax}}$ and $M_{\text {res }}$ which indicate the temperature at the maximum weight loss and the residual mass, respectively.

\section{Results and Discussions}

\subsection{Treated and Untreated Kaolinite Characterization}

3.1.1. Infrared Analysis. The unmodified kaolinite FTIR spectra shows the appearance in the hydroxyl zone of the bands at the following wave numbers: $3696,3674,3653$, and $3620 \mathrm{~cm}^{-1}$. As it is reported in Figure 1(a), the three first bands characterize, respectively, the outer hydroxyl groups vibrations. Also, the observation of the bands at 3674 and $3653 \mathrm{~cm}^{-1}$ confirms that the used kaolinite is a highly ordered mineral. The band at $3620 \mathrm{~cm}^{-1}$ corresponds to the inner hydroxyl groups which do not participate to the establishment of the hydrogen bonds responsible of the great cohesive energy of this clay. The Si-O- and $\mathrm{Si}-\mathrm{O}-\mathrm{Si}$ vibrations are illustrated by the bands at 1114, 1030, and $1006 \mathrm{~cm}^{-1}$ whereas the $\mathrm{Al}-\mathrm{OH}$ bond vibrations are visibly characterized by the bands appearing at the wave numbers $937,912,795$, and $756 \mathrm{~cm}^{-1}$. Additional broad stretching bands of kaolinite at 3400 , and $1630 \mathrm{~cm}^{-1}$ are attributed to the associated water adsorbed on the external surface.

The FTIR urea spectra (Figures 1(b)) exhibits bands between 3500 and $3100 \mathrm{~cm}^{-1}$ assigned to symmetric and asymmetric stretching vibrations of the N-H bonds, at 1683, 1630 and $1603 \mathrm{~cm}^{-1}$ characterizing the $\mathrm{C}=\mathrm{O}$ vibrations and a band at $1468 \mathrm{~cm}^{-1}$ representing the $\mathrm{C}-\mathrm{N}$ bond stretching.

The FTIR spectra of kaolinite/urea intercalate (Figure 1(c)) shows the bands at 3696 and $3620 \mathrm{~cm}^{-1}$ assigned to the kaolinite hydroxyls. The rest of the hydroxyl groups bands observed for the untreated kaolinite at 3674 and $3653 \mathrm{~cm}^{-1}$ are not present in this case due to the loss of hydrogen bonding between the layers. Makó et al. [17]

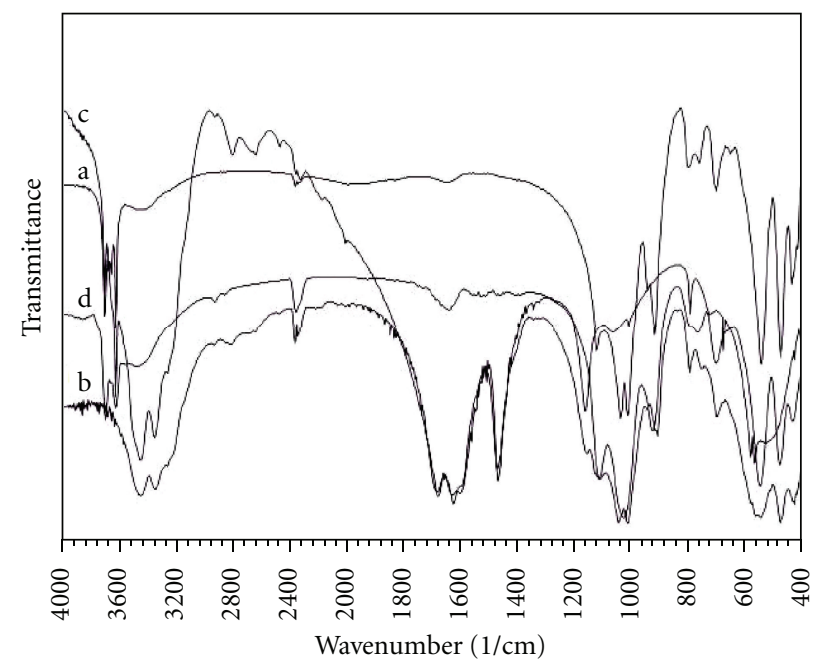

FIGURE 1: FTIR spectra of (a) neat kaolinite, (b) urea, (c) kaolin/ urea, and (d) kaolin/HDTMA.

proposed that the weakening of the $3696 \mathrm{~cm}^{-1}$ band compared to the $3620 \mathrm{~cm}^{-1}$ one, reflects hydrogen bonding between inner surface hydroxyls and urea molecules. Also, according to Ledoux and White [14], the new band detected at $3500 \mathrm{~cm}^{-1}$ results from hydrogen bonds formation between $\mathrm{NH}_{2}$ groups of urea and O-Si-O groups of kaolinite. In the domain $1400-1800 \mathrm{~cm}^{-1}$, the changes in urea vibrations bands in kaolinite/urea intercalate can also be followed. Valášková et al. [24] observed that the stretching vibration of $\mathrm{C}=\mathrm{O}$ groups is detected as for pure urea at $1683 \mathrm{~cm}^{-1}$, but the formation of hydrogen bonds with kaolinite hydroxyl groups shifts the stretching frequency of urea from $1630 \mathrm{~cm}^{-1}$ to $1617 \mathrm{~cm}^{-1}$. Makó et al. [17] noticed that the stretching vibration of urea $\mathrm{C}=\mathrm{O}$ groups, detected at $1673 \mathrm{~cm}^{-1}$, is shifted to a higher wave number in kaolinite/urea intercalate. The new band that they observed at $1683 \mathrm{~cm}^{-1}$ is due to the free $\mathrm{C}=\mathrm{O}$ vibration since the conjugation between the $\mathrm{C}=\mathrm{O}$ and $\mathrm{NH}$ groups no longer occurs and new hydrogen bonds are formed between the $\mathrm{NH}_{2}$ groups and oxygen atoms of the siloxane layer. In our material, the bands attributed to the urea binding in kaolinite are detected at $1683 \mathrm{~cm}^{-1}$ and $1627 \mathrm{~cm}^{-1}$ in the complex. According to the model of types of urea bonding to kaolinite, proposed by Makó et al. [17], the hydrogen bonds concerns the $\mathrm{NH}_{2}$ group attached to a free nonconjugated $\mathrm{C}=\mathrm{O}$ and the oxygen atom of the siloxane layer.

After treatment with the alkylammonium salt, the spectra reported in Figure 1(d) reveals no characteristic peaks of urea molecules bonded to kaolinite groups which is the proof that they have been totally displaced during the treatment with the ammonium salt. In addition, the FTIR spectra points out the presence of two new weak bands at approximately 2920 and $2850 \mathrm{~cm}^{-1}$ attributed, respectively, to the symmetric and asymmetric stretching vibrations of the $-\mathrm{CH}_{3}$ groups contained in the alkyl chains of the ammonium salt. These bands confirm the occurrence of interactions between the ammonium molecules and the kaolinite groups. The XRD results will greatly contribute to verify if these interactions 


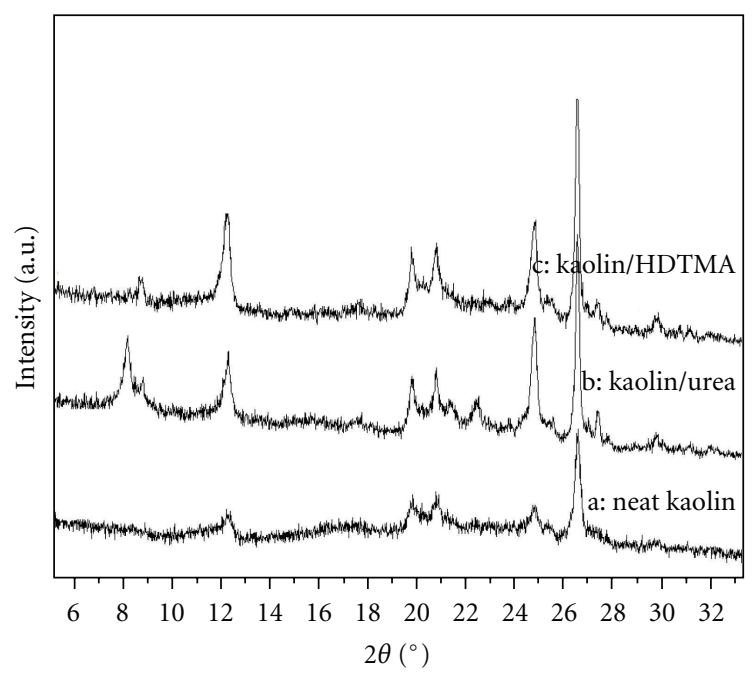

Figure 2: X-ray diffraction curves of neat kaolinite and kaolin/urea and kaolin/HDTMA mixtures.

involved the interlayer space functional groups or only those on the particle surface.

3.1.2. X-Ray Diffraction Results. The XRD patterns of the original and ground kaolinite are given in Figure 2: curve a in the figure displays the 001 reflection of the unmodified kaolinite at $(2 \theta) 12.39^{\circ}$, the corresponding $d$-spacing $7.20 \AA$ with a broad peak typical of a low-ordered kaolinite. In curve $\mathrm{b}$, two overlapping XRD peaks representing two types of the expanded structure appear at around $10.7 \AA$, and indicate the expansion of the kaolinite ground together with the solid urea. However, a significant peak intensity is left at the d-spacing $7.20 \AA$, implying only some $50 \%$ efficiency. The obtained results suggest that the mechanochemical intercalation slightly deforms the lattice structure and increases the ability of the kaolinite layers to be expanded by urea. Indeed, dry grinding of kaolinite ensures intimate contact between the external surface of kaolinite and the intercalating reagent. This process favours an elastic deformation of the layers and promotes the opening of the interlayer space for the access of the guest molecules.

Curve $\mathrm{c}$ of Figure 2, depicting the XRD pattern of the kaolinite treated with the alkylammonium salt in aqueous solution, shows that the treatment does not produce any detectable structural changes on the interlayer spacing of the clay. The use of the obtained kaolinite/urea complex failed in the intercalation of the ammonium salt in the interlayer gallery of the clay. So, it is clear now that the ammonium salt molecules interacted with the kaolinite hydroxyls groups involved at the surface of the clay particles and not with those situated in the interlayer space.

\subsection{Composites Mechanical Characterization}

3.2.1. Composites Impact Strength. The Izod impact strength variations of the PP composites notched samples filled with modified and unmodified kaolin are illustrated by Figure 3 .

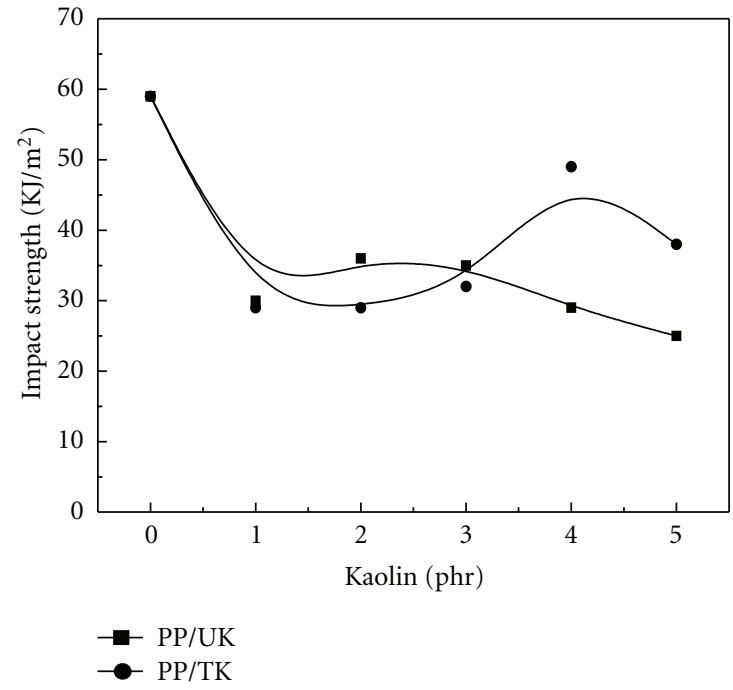

Figure 3: PP composites notched Izod impact strength variations as a function of treated and untreated kaolin concentration.

It appears that kaolinite incorporation to the thermoplastic matrix causes a marked decrease of its impact strength. This result is explained by the fact that the introduction of the mineral filler engenders an increase of rigidity and causes a high local stress concentration at the interface filler/matrix, attributed especially to aggregates formation which weakens the strength of all the material.

Because of the prominent dominance of these effects, the ammonium kaolinite treatment effect is not apparent. However, concerning the composites filled with 2 and $4 \mathrm{phr}$ of kaolinite modified with 2 and $4 \%$ of silane coupling agent, we concluded that their Izod impact strength is higher than those containing the same concentration of the unmodified kaolin, as it is reported in Table 2. This observation supports the establishment of interactions between the silane coupling agent molecules and the kaolinite superficial hydroxyl groups which contribute the get a better adhesion between the matrix and the mineral filler and allow the achievement of better composites impact strengths.

3.2.2. Composites Tensile Properties. Figures 4 and 5 depict the tensile characteristics variations for the composites prepared with unmodified kaolin and with kaolin treated with the alkylammonium salt. Thus, it appears from the Figure 4 that the yielding stress and strain values are slightly affected by kaolinite treatment and concentration.

The composites yielding behavior is essentially governed by the PP matrix due to the low rate of the incorporated mineral filler. However, it seems important to note that the values of the yielding strain of all the composites are higher than those of the matrix, probably because of the rigidity of the clay.

Figure 5 illustrates the variations of the stress and the strain at break as function of the filler rate for the composites with treated and untreated kaolin. The behavior at break of the composites has been markedly affected by the incorporation of the mineral filler. Thus, the strain noticeable decrease 
TABle 2: Mechanical characteristics of PP/kaolin composites as a function of kaolin and silane concentrations.

\begin{tabular}{lcccccccccc}
\hline $\begin{array}{l}\text { Kaolin } \\
\text { (phr) }\end{array}$ & \multicolumn{1}{c}{2} & \multicolumn{3}{c}{4} \\
\hline Z6020 $(\%)$ & $\sigma_{y}(\mathrm{MPa})$ & $\varepsilon_{y}(\%)$ & $\sigma_{r}(\mathrm{MPa})$ & $\varepsilon_{r}(\%)$ & $a_{k}\left(\mathrm{KJ} / \mathrm{m}^{2}\right)$ & $\sigma_{y}(\mathrm{MPa})$ & $\varepsilon_{y}(\%)$ & $\sigma_{r}(\mathrm{MPa})$ & $\varepsilon_{r}(\%)$ & $a_{k}\left(\mathrm{KJ} / \mathrm{m}^{2}\right)$ \\
\hline 2 & 23 & 13 & 17 & 650 & 44 & 23 & 11 & 17 & 650 & 35 \\
4 & 23 & 11 & 17 & 600 & 43 & 23 & 9 & 17 & 530 & 41 \\
\hline
\end{tabular}

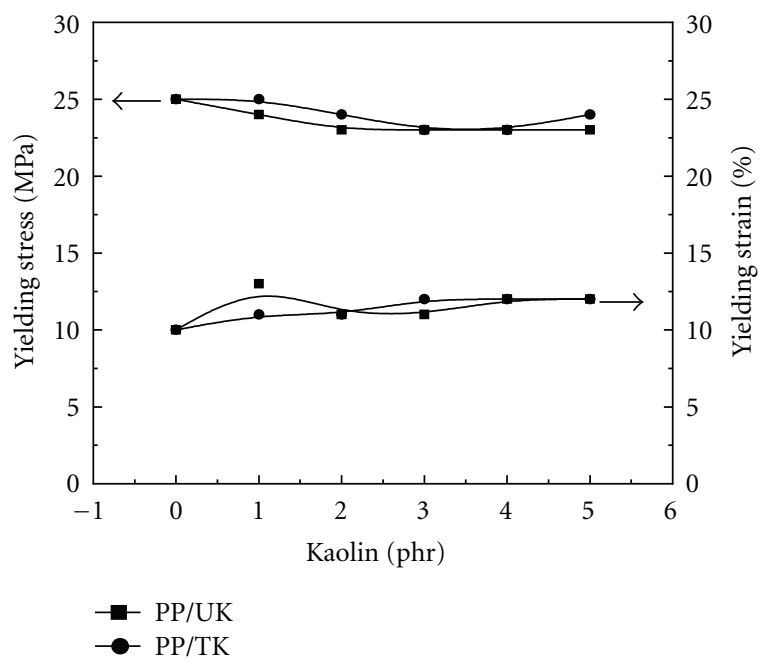

Figure 4: PP composites yielding stress and strain variations as a function of treated and untreated kaolin concentration.

occurred from $600 \%$ for the nonfilled PP to a value of $60 \%$ for the composites with $5 \mathrm{phr}$ of untreated kaolin and to $27 \%$ for that containing the same concentration of the filler treated with the alkylammonium salt. The decrease of the strain at break at this filler loading might be due to the decreased deformability at the interface the filler/matrix.

For the composites with 2 and $4 \mathrm{phr}$ of kaolin treated with 2 and $4 \%$ of silane, the Table 2 shows that practically small variations of the tensile characteristics $\sigma_{y}, \varepsilon_{y}, \sigma_{r}, \varepsilon_{r}$ are detected as a function of the kaolin and the coupling agent concentrations. Thus, it appears evident that these two low kaolin contents, even treated with the ammonium salt and the silane coupling agent cannot affect noticeably the matrix properties.

3.3. Melting and Crystallization Behaviors. Figures 6 and 7 compare the DSC cooling thermograms of neat PP with its various composites. In Figures 6(a), the effects of adding unmodified kaolin on the crystallization of PP are evident. The crystallization onset temperature $T_{o}$ and the crystallization peak temperature $T_{c}$ (temperature at the exotherm maximum) of PP, both shifted to lower temperatures as kaolin is added. The decrease in the crystallization temperature after introduction of the filler means that higher undercooling of the melt is necessary for the crystallization to occur [25]. We believe that the reason of this behaviour is the strong influence of the kaolinite on the chain dynamics. Although fillers usually act as nucleation centers [26], the

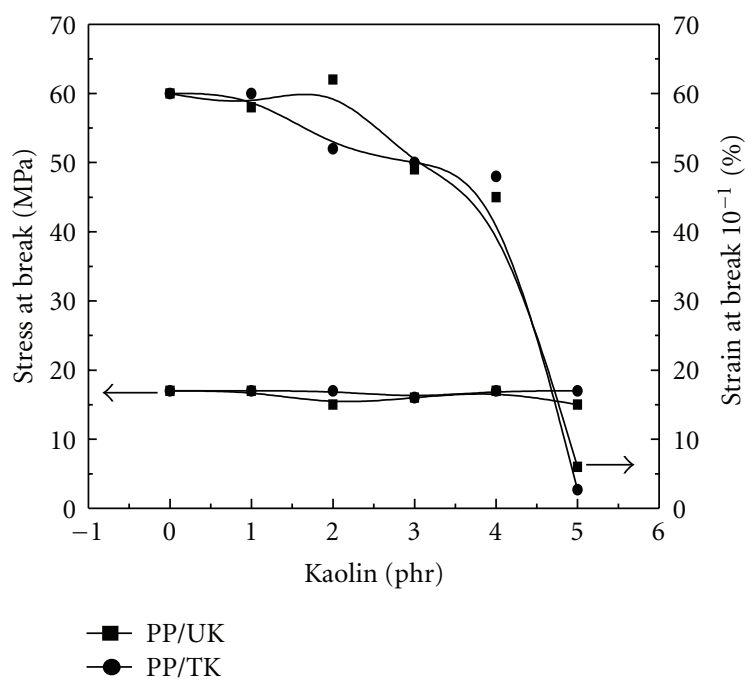

FIGURE 5: PP composites breaking stress and strain variations as a function of treated and untreated kaolin concentration.

crystallization in the present system is slowed down as a result of lower chain mobility.

Figures 6(b) depicts the DSC cooling thermograms of neat $\mathrm{PP}$ and its ammonium modified kaolin composites. The crystallization retarding effect of the filler is still observed, but it is more obvious for the clay loadings of 4 and $5 \mathrm{phr}$, so the shifting of the crystallization temperature increases proportionally to the clay concentration. When comparing the thermograms of the composites including the three first modified kaolin loadings $(1,2$, and $3 \mathrm{phr})$, with those of the composites containing the equivalent rates of the unmodified clay, we notice that the values of $T_{o}$ and $T_{c}$ are slightly lower to the matrix ones but sufficiently higher to those of the composites PP/unmodified kaolin. This observation indicates that the crystallization rate increases and the degree of supercooling required for the crystallization reduces when the modified clay is added. This fact can merely be linked to the treatment and to the interactions between the kaolinite modified surface and PP chains. Thus, the combined effect of the clay and of the interactions clay/matrix contributes to get an enhanced PP chains mobility and consequently a faster crystallization rate and higher crystallization temperatures, relatively to untreated kaolin composites. For the composites with 4 and $5 \mathrm{phr}$ of kaolin, the effect of the clay loading is more prominent and the retarding effect is much more pronounced.

The crystallization behaviour of silane modified kaolinite composites exhibited the similar trend as above, as it is seen 


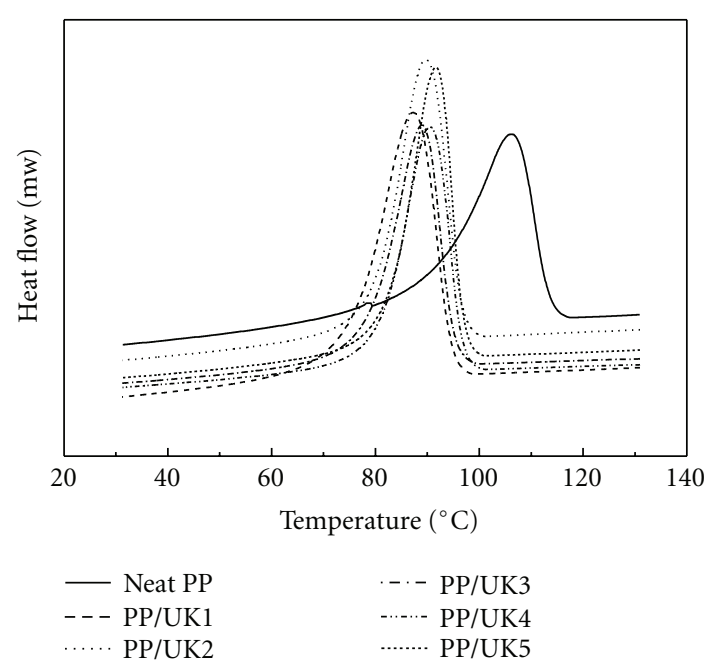

(a)

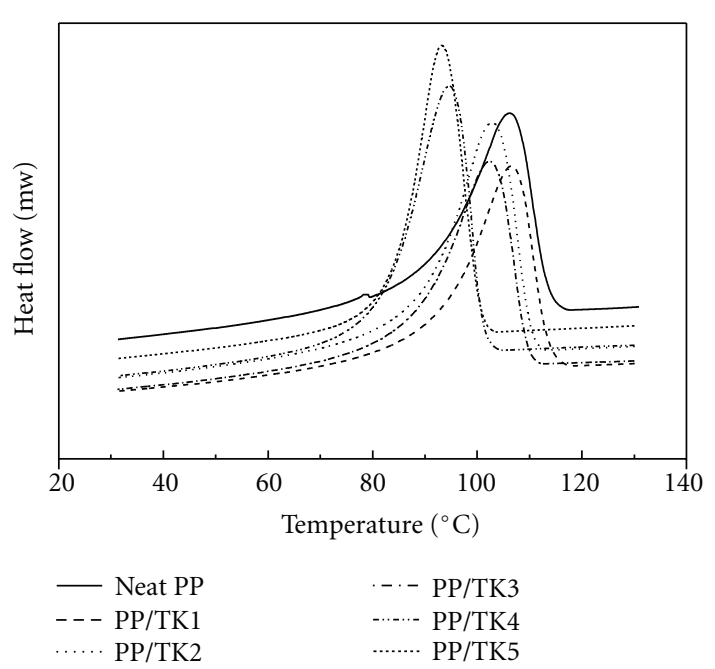

(b)

Figure 6: DSC thermograms of (a) PP/untreated kaolin and (b) PP/treated kaolin cooled from the melt at $20^{\circ} \mathrm{C} / \mathrm{min}$.

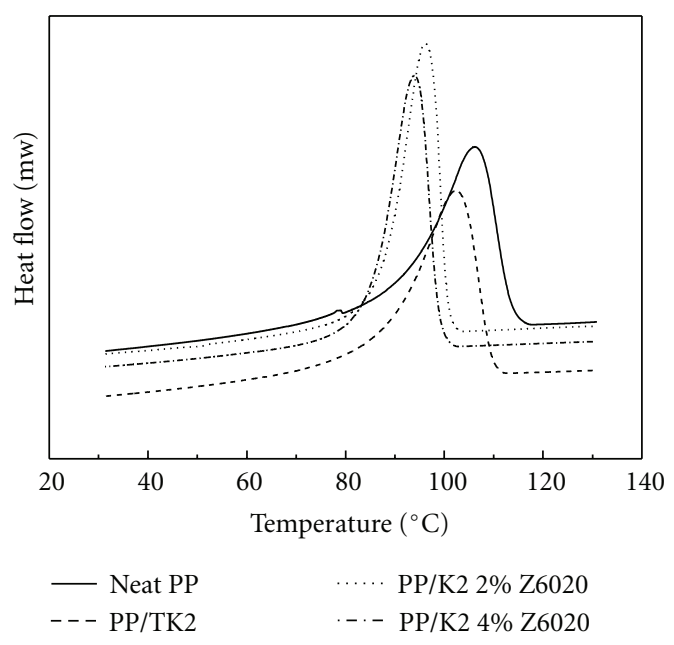

(a)

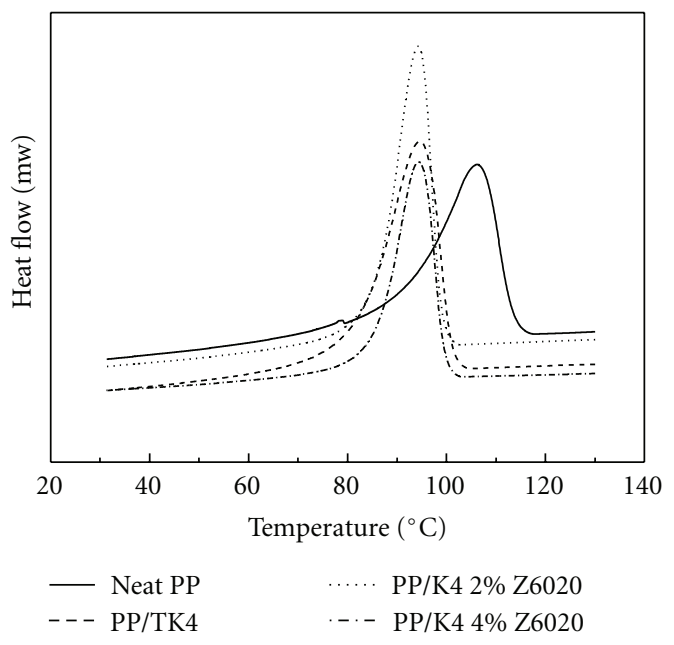

(b)

FIGURE 7: DSC thermograms of PP composites containing (a) 2 phr and (b) 4 phr of kaolinite treated with 2\% and $4 \%$ of silane, cooled from the melt at $20^{\circ} \mathrm{C} / \mathrm{min}$.

in Figures 7(a) and 7(b). In this case also, the surface treatment of the filler caused the variation of $T_{c}$. The effect of the coupling agent concentration is unnoticeable. Additionally, the crystallization heat $\Delta H_{c}$ varied insignificantly for all the composites samples.

Figures $8(\mathrm{a})$ and $8(\mathrm{~b})$ represent the DSC heating thermograms of neat $\mathrm{PP}$ and its composites heated from ambient temperature to $250^{\circ} \mathrm{C}$ at $10^{\circ} \mathrm{C} / \mathrm{min}$. The melting peak temperatures $T_{m}$ of the untreated and ammonium treated kaolin composites vary trivially with respect to that of neat PP. This result suggests that the addition of small kaolin concentrations and its treatment did not affect the structure and the stability of the formed PP crystals.

Similar melting peak results are observed in the case of the silane surface treated kaolin composites, as it is illustrated in Figures 9(a) and 9(b). So, from the observed thermograms, it seems that the surface treatment of the filler has a small effect on the melting temperature and on the crystallinity of the matrix.

These results indicate that the incorporation and the modification of the filler apparently affect the PP crystallization rate, but influence the PP crystallinity only slightly, as it is reported in the Table 3.

3.4. Composites Thermal Stability. TGA was employed to evaluate thermal stabilities of the different formulated samples which degradation characteristics are reported in the Table 4. When considering the matrix and the composites with untreated kaolin, the main deductions can be summarized as follows. The used PP started to degrade around $250^{\circ} \mathrm{C}$, and finishes at $393^{\circ} \mathrm{C}$ with approximately no 


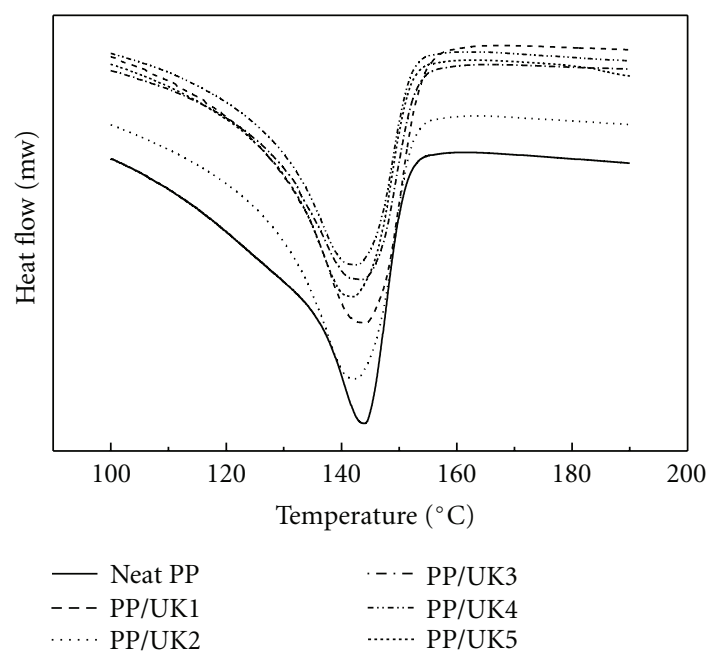

(a)

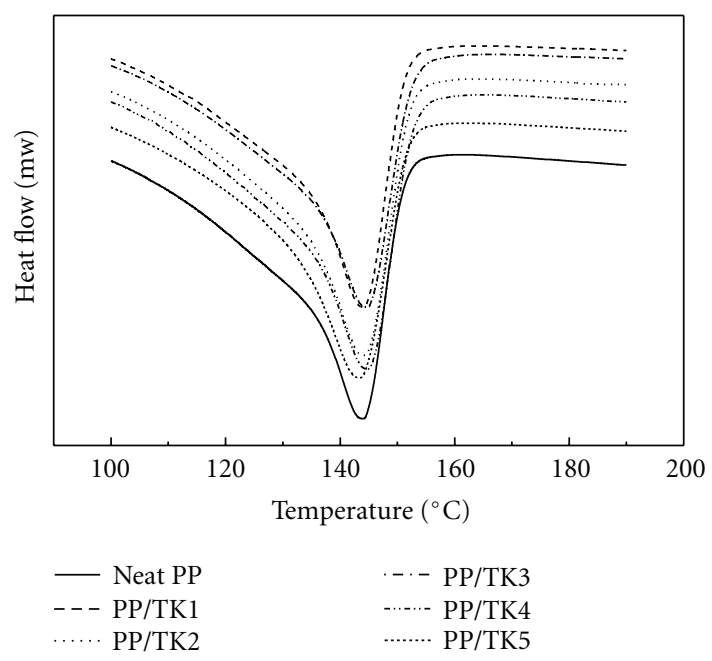

(b)

FiguRE 8: DSC heating thermograms of (a) PP/untreated kaolin and (b) PP/treated kaolin composites.

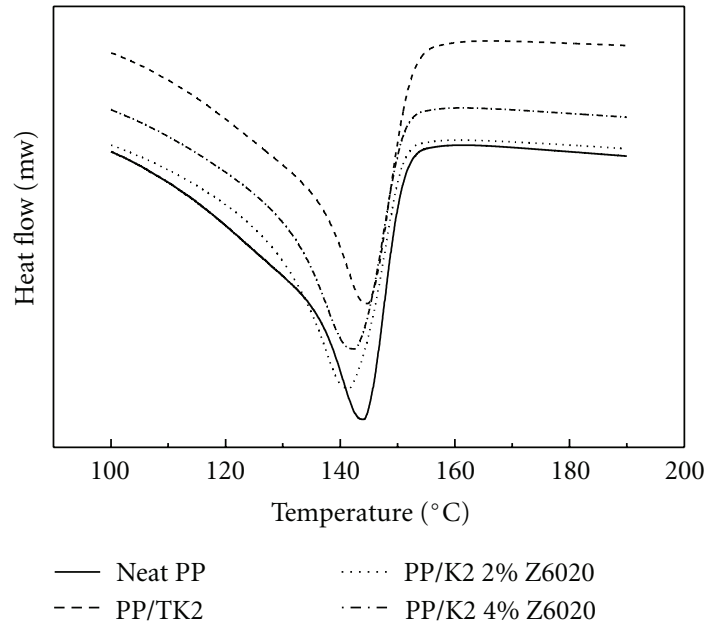

(a)

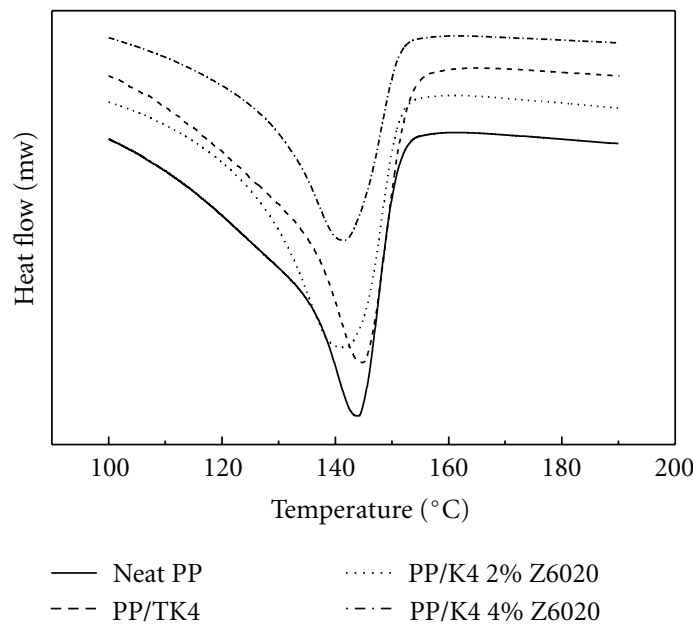

(b)

FIGURE 9: DSC heating thermograms of PP composites containing (a) 2 phr and (b) 4 phr of kaolinite treated with $2 \%$ and $4 \%$ of silane.

residual mass. The PP/untreated kaolin composites showed almost an identical thermal stability and as the PP matrix, they are decomposed on only one stage. All the composites started degradation at $250^{\circ} \mathrm{C}$, however; a noticeable increase is observed on the value of the temperature at which the degradation is achieved $T_{\mathrm{df}}$. For example, the composite including $5 \mathrm{phr}$ of kaolin begins to degrade at $250^{\circ} \mathrm{C}$ and finished at $405^{\circ} \mathrm{C}$, with a residual mass around $5.5 \%$, which is approximately the clay loading in the composite. $T_{\mathrm{dmax}}$ exhibit the same variations as $T_{\mathrm{df}}$ because it increases when the kaolin concentration increases. Indeed, $T_{\mathrm{dmax}}$ varies from $374^{\circ} \mathrm{C}$ for neat $\mathrm{PP}$ to $389^{\circ} \mathrm{C}$ for the formulation including $5 \mathrm{phr}$ of kaolinite. These observations suggest that the addition of small amounts of the filler enhances noticeably the thermal stability of the whole material [27].

The thermal stability of the $\mathrm{PP} /$ modified kaolin composites, exhibited a similar trend as the above ones. All the formulations started degradation around $250^{\circ} \mathrm{C}$ and finishes with a residual mass equivalent to the clay loading in the composites. $T_{\mathrm{df}}$ and $T_{\mathrm{dmax}}$ showed an enhancement relative to the matrix, but no variations were noticed when compared to the composites with unmodified clay. So, the thermal stability enhancement is mainly due to the clay, and small effects were noticed after the modification with the ammonium salt and the silane coupling agent.

\section{Conclusion}

This article reports the results of an investigation on the effects of kaolin loading and treatments with an alkylammonium salt and a silane coupling agent, on the mechanical and thermal properties of polypropylene.

Infrared analysis results supported the occurrence of a partial delamination during dry milling of kaolin with urea 
TABLE 3: PP/kaolin composites thermal characteristics determined from DSC scans.

\begin{tabular}{lccccc}
\hline Samples & $\begin{array}{c}\Delta H_{m} \\
(\mathrm{~J} / \mathrm{g})\end{array}$ & $\begin{array}{c}T_{m} \\
\left({ }^{\circ} \mathrm{C}\right)\end{array}$ & $\begin{array}{c}\Delta H_{c} \\
(\mathrm{~J} / \mathrm{g})\end{array}$ & $\begin{array}{c}T_{c} \\
\left({ }^{\circ} \mathrm{C}\right)\end{array}$ & $\begin{array}{c}x_{c} \\
(\%)\end{array}$ \\
\hline Neat PP & 63 & 144 & 68 & 106 & 41 \\
\hline PP/UK1 & 56 & 143 & 60 & 88 & 36 \\
PP/UK2 & 65 & 142 & 65 & 90 & 39 \\
PP/UK3 & 59 & 143 & 61 & 89 & 37 \\
PP/UK4 & 54 & 143 & 65 & 90 & 39 \\
PP/UK5 & 63 & 142 & 65 & 91 & 39 \\
\hline PP/TK1 & 60 & 143 & 67 & 106 & 40 \\
PP/TK2 & 63 & 144 & 63 & 102 & 38 \\
PP/TK3 & 57 & 144 & 58 & 102 & 35 \\
PP/TK4 & 57 & 144 & 58 & 95 & 35 \\
PP/TK5 & 59 & 143 & 65 & 93 & 39 \\
\hline PP/K2 2\% Z6020 & 63 & 141 & 70 & 96 & 42 \\
PP/K2 4\% Z6020 & 65 & 142 & 67 & 94 & 40 \\
PP/K4 2\% Z6020 & 55 & 141 & 64 & 94 & 38 \\
PP/K4 4\% Z6020 & 59 & 142 & 66 & 94 & 40 \\
\hline
\end{tabular}

TABLE 4: PP/kaolin composites degradation characteristics determined from TGA scans.

\begin{tabular}{lccc}
\hline Samples & $T_{\mathrm{d} 0}\left({ }^{\circ} \mathrm{C}\right)$ & $T_{\mathrm{dmax}}\left({ }^{\circ} \mathrm{C}\right)$ & $T_{\mathrm{df}}\left({ }^{\circ} \mathrm{C}\right)$ \\
\hline Neat PP & 250 & 374 & 393 \\
\hline PP/UK1 & 250 & 380 & 395 \\
PP/UK2 & 249 & 383 & 400 \\
PP/UK3 & 252 & 386 & 404 \\
PP/UK4 & 247 & 384 & 403 \\
PP/UK5 & 250 & 389 & 405 \\
\hline PP/TK1 & 252 & 376 & 394 \\
PP/TK2 & 250 & 370 & 398 \\
PP/TK3 & 253 & 377 & 394 \\
PP/TK4 & 250 & 387 & 403 \\
PP/TK5 & 248 & 388 & 404 \\
\hline PP/K2 2\% Z6020 & 245 & 382 & 397 \\
PP/K2 4\% Z6020 & 245 & 384 & 400 \\
PP/K4 2\% Z6020 & 245 & 387 & 400 \\
PP/K4 4\% Z6020 & 245 & 388 & 400 \\
\hline
\end{tabular}

and the bonding of alkylammonium to its groups. The Xrays diffraction confirmed that the 001 reflection of the clay was not affected by the treatment, which states that the interactions concerned essentially the superficial groups of kaolinite via an adsorption process.

The mechanical characterization showed the decrease of the PP/kaolin composites impact strength due to aggregates formation and to the poor adhesion between the filler surface and the matrix. In the opposite, small variations were observed on the tensile characteristics, except for the composites with $5 \mathrm{phr}$ of kaolinite, for which a strong decrease of the strain at break was noticed.
The DSC results indicated that the addition of modified and unmodified kaolin causes small variations on the crystallinity and on the melting temperature of the matrix. However, noticeable variations are deduced on the crystallization temperature which is shifted to lower values when the filler is added. The crystallization inhibiting effect of the kaolin filler is essentially pointed out on the crystallization temperature without affecting considerably the degree of crystallinity of the matrix. Also, the TGA results confirmed a slight enhancement of the thermal stability of the composites relative to the neat matrix.

\section{References}

[1] Y. Wang and J. J. Wang, "Shear yield behavior of calcium carbonate-filled polypropylene," Polymer Engineering and Science, vol. 39, no. 1, pp. 190-198, 1999.

[2] G. Guerrica-Echevarria, J. I. Eguiazabal, and J. Nazabal, "Influence of molding conditions and talc content on the properties of polypropylene composites," European Polymer Journal, vol. 34, no. 8, pp. 1213-1219, 1998.

[3] A. Usoki, M. Kato, A. Okada, and T. Kurauchi, "Synthesis of polypropylene-clay hybrid," Journal of Applied Polymer Science, vol. 63, no. 1, pp. 137-139, 1997.

[4] A. C. Chinellato, S. E. Vidotti, G. H. Hu, and L. A. Pessan, "An acrylic acid modified polypropylene as a compatibilizing agent for the intercalation/exfoliation of an organically modified montmorillonite in polypropylene," Journal of Polymer Science $B$, vol. 46, no. 17, pp. 1811-1819, 2008.

[5] H. H. Murray, "Traditional and new applications for kaolin, smectite, and palygorskite: a general overview," Applied Clay Science, vol. 17, no. 5-6, pp. 207-221, 2000.

[6] H. H. Murray, "Applied clay mineralogy today and tomorrow," Clay Minerals, vol. 34, no. 1, pp. 39-49, 1999.

[7] L. Cabedo, E. Giménez, J. M. Lagaron, R. Gavara, and J. J. Saura, "Development of EVOH-kaolinite nanocomposites," Polymer, vol. 45, no. 15, pp. 5233-5238, 2004.

[8] S. Olejnik, A. M. Posner, and J. P. Quirk, "The intercalation of polar organic compounds into kaolinite," Clay Minerals, vol. 8, pp. 421-434, 1970.

[9] Y. Komori, Y. Sugahara, and K. Kuroda, "Direct intercalation of poly(vinylpyrrolidone) into kaolinite by a refined guest displacement method," Chemistry of Materials, vol. 11, no. 1, pp. 3-6, 1999.

[10] W. N. Martens, R. L. Frost, J. Kristof, and E. Horvath, "Modification of kaolinite surfaces through intercalation with deuterated dimethylsulfoxide," Journal of Physical Chemistry B, vol. 106 , no. 16, pp. 4162-4171, 2002.

[11] E. Horváth, J. Kristóf, R. L. Frost, E. Jakab, É. Makó, and V. Vágvölgyi, "Identification of superactive centers in thermally treated formamide-intercalated kaolinite," Journal of Colloid and Interface Science, vol. 289, no. 1, pp. 132-138, 2005.

[12] R. L. Frost, J. Kristof, E. Horvath, and J. T. Kloprogge, "Modification of kaolinite surfaces through intercalation with potassium acetate, II," Journal of Colloid and Interface Science, vol. 214, no. 1, pp. 109-117, 1999.

[13] J. C. Dai and J. T. Huang, "Surface modification of clays and clay-rubber composite," Applied Clay Science, vol. 15, no. 1-2, pp. 51-65, 1999.

[14] R. L. Ledoux and J. L. White, "Infrared studies of hydrogen bonding interaction between kaolinite surfaces and intercalated potassium acetate, hydrazine, formamide, and urea," 
Journal of Colloid And Interface Science, vol. 21, no. 2, pp. 127152, 1966.

[15] R. L. Frost, J. Kristof, L. Rintoul, and J. T. Kloprogge, "Raman spectroscopy of urea and urea-intercalated kaolinites at $77 \mathrm{~K}$," Spectrochimica Acta A, vol. 56, no. 9, pp. 1681-1691, 2000.

[16] R. L. Frost, T. H. Tran, and J. Kristof, "The structure of an intercalated ordered kaolinite - A Raman microscopy study," Clay Minerals, vol. 32, no. 4, pp. 587-596, 1997.

[17] E. Makó, J. Kristóf, E. Horváth, and V. Vágvölgyi, "Kaoliniteurea complexes obtained by mechanochemical and aqueous suspension techniques-A comparative study," Journal of Colloid and Interface Science, vol. 330, no. 2, pp. 367-373, 2009.

[18] F. C. Chiu, S. M. Lai, J. W. Chen, and P. H. Chu, "Combined effects of clay modifications and compatibilizers on the formation and physical properties of melt-mixed polypropylene/clay nanocomposites," Journal of Polymer Science B, vol. 42, no. 22, pp. 4139-4150, 2004.

[19] F. Bellucci, A. Terenzi, A. Leuteritz et al., "Intercalation degree in PP/organoclay nanocomposites: role of surfactant structure," Polymers for Advanced Technologies, vol. 19, no. 6, pp. 547-555, 2008.

[20] O. Monticelli, Z. Musina, A. Frache, F. Bellucci, G. Camino, and S. Russo, "Influence of compatibilizer degradation on formation and properties of PA6/organoclay nanocomposites," Polymer Degradation and Stability, vol. 92, no. 3, pp. 370-378, 2007.

[21] T. S. Ellis and J. S. D'Angelo, “Thermal and mechanical properties of a polypropylene nanocomposite," Journal of Applied Polymer Science, vol. 90, no. 6, pp. 1639-1647, 2003.

[22] S. Letaief, T. A. Elbokl, and C. Detellier, "Reactivity of ionic liquids with kaolinite: melt intersalation of ethyl pyridinium chloride in an urea-kaolinite pre-intercalate," Journal of Colloid and Interface Science, vol. 302, no. 1, pp. 254-258, 2006.

[23] B. Wunderlich, Macromolecular Physics, vol. 3, Academic Press, New York, NY, USA, 1980.

[24] M. Valášková, M. Rieder, V. Matějka, P. Čapková, and A. Slíva, "Exfoliation/delamination of kaolinite by low-temperature washing of kaolinite-urea intercalates," Applied Clay Science, vol. 35, no. 1-2, pp. 108-118, 2007.

[25] A. S. Luyt, M. D. Dramićanin, Ž. Antić, and V. Djoković, "Morphology, mechanical and thermal properties of composites of polypropylene and nanostructured wollastonite filler," Polymer Testing, vol. 28, no. 3, pp. 348-356, 2009.

[26] J. Njuguna, K. Pielichowski, and S. Desai, "Nanofiller-reinforced polymer nanocomposites," Polymers for Advanced Technologies, vol. 19, no. 8, pp. 947-959, 2008.

[27] M. L. Lopez-Quintanilla, S. Sánchez-Valdés, L. F. R. de Valle, and F. J. Medellin-Rodriguez, "Effect of some compatibilizing agents on clay dispersion of polypropylene-clay nanocomposites," Journal of Applied Polymer Science, vol. 100, no. 6, pp. 4748-4756, 2006. 

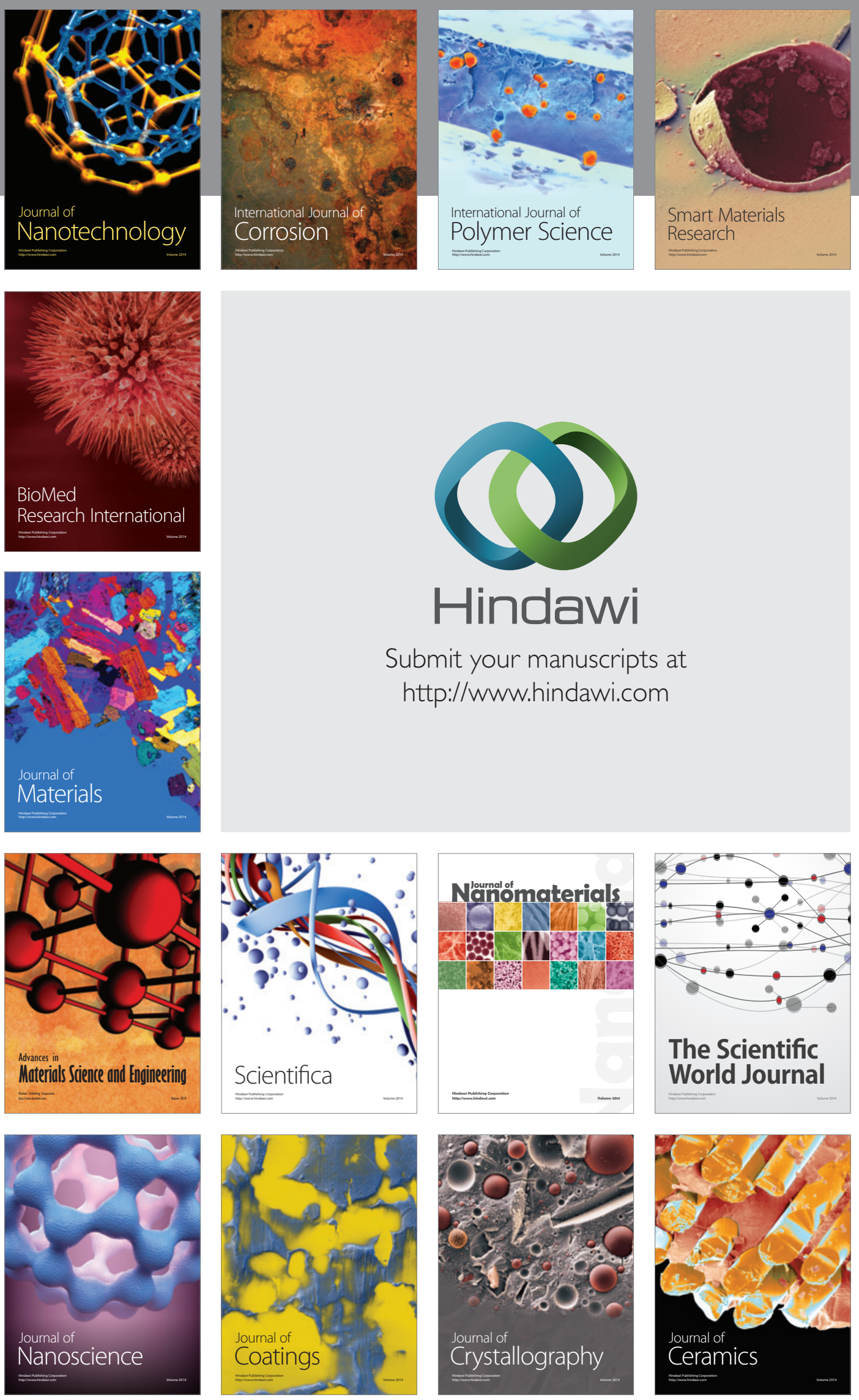

The Scientific World Journal

Submit your manuscripts at

http://www.hindawi.com

\section{World Journal}

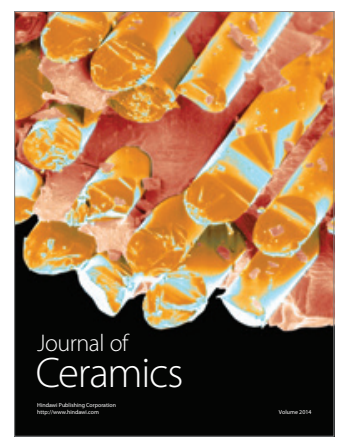

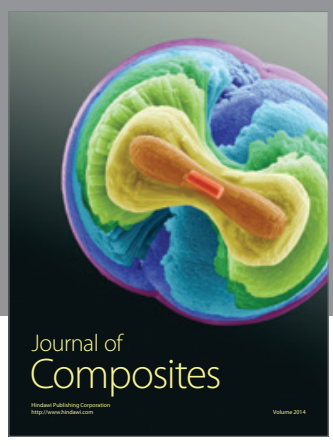
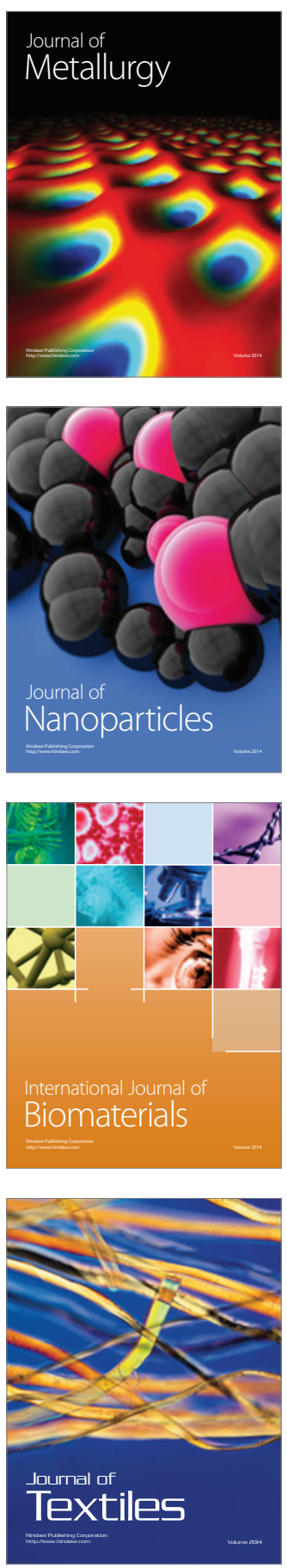